\title{
O ESTUDO DA LINGUAGEM EM SEU CONTEXTO SOCIAL: UM DIÁLOGO ENTRE BAKHTIN E LABOV
}

(The study of language in social context: a dialogue between Bakhtin and Labov)

Cristine Gorski Severo (UFGD)

RESUMO: Apesar de os dois teóricos sociais da linguagem, Bakbtin e Labov, serem oriundos de tradições diferentes - filosófica e empírica, respectivamente -, o artigo mostra a comparabilidade das duas abordagens, em termos de aproximações e distanciamentos, em relação aos seguintes aspectos: (i) "teoria sociológica"; (ii) metodologia de pesquisa e visão de sujeito; (iii) variação/mudança lingüística e variação estilística; e (iv) relação estabelecida entre língua, sociedade e identidade. Conclui-se que uma abordagem que articule as duas teorias é viável desde que a concepção de língua adotada relacione, intrinsecamente, o funcionamento da língua, a questão da identidade e o mundo social. PALAVRAS-CHAVE: Bakbtin; Labov; língua; sociedade.

ABSTRACT: Despite the fact that Bakhtin and Labov, who are two social theorists of language, share different traditions (philosophical and empirical ones, respectively), this article shows the comparability of these two approaches, in terms of approximations and distances, in relation to the following aspects: (i) the "sociological theory"; (ii) the research methodology and a certain subject's conception; (iii) the linguistic variation/ change and the stylistic variation; and (iv) the relation established between language, society and identity. We conclude that an approach that combines both theories is possible only if the language conception adopted is intrinsically related to: the way language functions, the identity aspect and the social world.

KEY-WORDS: Bakhtin; Labov; language; society.

\section{Introdução ${ }^{1}$}

Mikhail Bakhtin (1895-1975) e William Labov (1927-) podem ser considerados autores fundantes da sociolingüística russa e americana, res-

1. Este artigo consiste numa discussão revisada de parte de minha tese de doutorado (SEVERO 2007). 
pectivamente, dada a sua representatividade. Embora possuam histórias e percursos diferentes ${ }^{2}$, ambos se interessam pela linguagem como um fenômeno social, heterogêneo e plural: além de compartilharem divergências face à lingüística saussuriana, Bakhtin e Labov se ocupam das "margens", seja pelas idéias do primeiro acerca do plurilingüismo, seja pelo interesse do segundo pelos dialetos falados pelos negros americanos $\left(\mathrm{BEV}^{3}\right)$. Apesar de trilharem caminhos quase opostos - Bakhtin/Voloshinov, nos anos 20 (séc. XX) na antiga União Soviética, aprofundou-se nos estudos da linguagem a partir de um viés social-marxista, enquanto Labov, nos anos 60 (séc. $\mathrm{XX}$ ) nos Estados Unidos, optou por aspectos da sociologia de Durkheim, pelo empirismo e pela pesquisa quantitativa -, e de a filosofia de Bakhtin diferir, em muitos aspectos, do cientificismo de Labov; ou seja, apesar de os dois falarem de posições teóricas diferentes, é possível estabelecer uma relação dialógica entre eles ${ }^{4}$. Ambos os teóricos compartilham certas premissas referentes ao estudo da linguagem: a fala/comunicação verbal é primordial para o estudo da língua; a variação/mudança é própria da língua; a língua é um fenômeno social; há leis (de ordem social e econômica) que regem a mudança lingüística.

O objetivo deste artigo é, então, promover um diálogo entre as idéias de Bakhtin e de Labov - incluindo aproximações e distanciamentos -, com vistas a contribuir para as discussões e articulações teóricas em torno de uma perspectiva social da língua. A questão de caráter geral que emerge é a seguinte: é possível desenvolver um trabalho articulando as duas teorias? A resposta é, hipoteticamente, afirmativa, desde que a visão de língua adotada pelo pesquisador relacione de forma intrínseca o processo de funcionamento da língua (variação/mudança e estabilidade), a realidade social e a questão do sujeito/identidade.

O texto se organiza em torno dos seguintes tópicos: (i) uma contextualização da vertente sociológica presente nos trabalhos de Bakhtin e de Labov; considerações acerca (ii) da metodologia e da questão do sujeito;

2. A formação de Bakhtin se deu num meio filosófico, artístico, político e religioso, enquanto Labov graduou-se em inglês e filosofia, estudou química e centrou seu interesse na sistematização da variação e mudança lingüística.

3. Black English Vernacular.

4. O estabelecimento desse "diálogo" pode ser interessante, considerando que Labov e Bakhtin são amplamente lidos e tomados como referência nos estudos lingüísticos no Brasil, em diferentes áreas (notadamente, Sociolingüística e Lingüística Aplicada). 
(iii) da variação/mudança lingüística; e (iv) da relação entre língua, identidade e sociedade.

\section{As tradições sociológicas de Bakhtin e de Labov}

Os trabalhos iniciais de Bakhtin e do seu Círculo sofreram fortes influências da vertente sociológica-marxista presente nos estudos da linguagem no primeiro quarto do século XX na Rússia (posteriormente, União Soviética). Algumas dessas influências são originárias dos trabalhos de Iakubinskii ${ }^{5}$ e podem ser resumidas nos seguintes aspectos (Brandist 2006; Lähteenmäkï 2005; 2006):

(i) a língua possui duas funções interdependentes - forma e ideologia; no desenvolvimento das línguas essas duas funções podem estar em contradição, determinada pela realidade socioeconômica;

(ii) a língua expressa uma luta entre forças centralizadoras e descentralizadoras; tal luta determina o vetor histórico das línguas e caracteriza a estratificação da língua em linguagens socioideológicas. Esse confronto espelha a relação dialética existente entre a forma de comunicação e o conteúdo ideológico;

(iii) os gêneros do discurso estão vinculados a modos sociais de interação verbal constituídos historicamente. Enquanto na ótica de Iakubinskii essa noção foi desenvolvida à luz das relações discursivas presentes no capitalismo russo, para Bakhtin os gêneros discursivos foram trabalhados, inicialmente, sob a perspectiva da história literária (o romance);

(iv) a pluralidade discursiva - estratificação social da língua - aparece nos gêneros paródicos (o romance é o gênero paródico por excelência) e existe em decorrência da natureza contraditória e tensa da realidade social. Essa idéia, na visão de Bakhtin, é apresentada a partir dos estudos da literatura na Idade Média e, para Iakubinskii, é desenvolvida tendo como escopo as relações capitalistas na Rússia agrária;

5. Iakubinskii foi discípulo de Baudouin de Courtenay e, junto com outros estudiosos, freqüentava o Instituto de Estudos Comparados das Literaturas e Línguas do Ocidente e do Oriente (ILIaZV), em Leningrado, onde também estiveram Voloshinov e Medvedev (integrantes do Círculo de Bakhtin) no final da década de 1920. Esses lingüistas do ILIaZV (1924-1930) pretendiam definir uma base sociológica para os trabalhos de dialetologia dos estudiosos pré-revolucionários, a partir das idéias de Marx, Engels, Lênin e Marr. (Brandist, 2006) Iakubinskii orientou Voloshinov na Universidade de Petrogrado (1922-1924) e realizaram alguns trabalhos juntos; daí a influência daquele na concepção dialógica do enunciado, visto que Iakubinskii havia publicado um artigo intitulado "Sobre o Discurso Dialógico", em 1923. Entre 1930 e 1937 o ILIaZV se tornou GIRK (Instituto Nacional de Cultura Discursiva), tendo sido reconhecido pelos estudos em dialetologia e história da formação das línguas nacionais (Brandist, 2005; Lähteenmäkï, 2005). 
(v) os trabalhadores tomam consciência da estratificação social da língua (discurso), devido à democratização dos gêneros discursivos operada pelo líder político (o proletariado). Essa democratização lingüística é localizada por Iakubinskii na Revolução de 1917 e por Bakhtin no Renascimento.

Já a abordagem de Labov segue uma outra direção, com clara influência de Meillet (1866-1936) e, sobretudo, de Durkheim (1858-1917), conforme se observa na afirmação de Figueroa (1994: 76): "Sabe-se que Labov é familiarizado com Durkheim, que ele utiliza o termo fato social, que ele aceita a língua como fato social" ${ }^{10}$. No caso, os fatos sociais referem-se a "maneiras de agir, de pensar e de sentir que apresentam a propriedade marcante de existir fora das consciências individuais [...] são dotados de um poder imperativo e coercitivo" (Durkheim 1973: 2).

Há uma tensão presente na teoria de Durkheim entre indivíduo e sociedade que também aparece, de certa forma, nos trabalhos de Labov: nenhum dos dois assume que o indivíduo seja totalmente submetido aos fatos sociais (à linguagem, no caso de Labov), que deva aceitá-los por serem impostos de forma coercitiva. Durkheim defende a existência do ator social que (i) possui uma certa consciência dos fenômenos sociais e (ii) é agente no funcionamento da sociedade. Assim, a idéia de "coação" presente na noção de fato social de Durkheim não impede que a vida social seja "tanto 'coercitiva' quanto 'espontânea”' (Giddens 1998: 157). Labov parece ter absorvido essas duas implicações (i e ii) da noção de fato social de Durkheim $^{7}$.

Resumindo, Bakhtin e Labov se vinculam a tradições sociológicas diferentes: enquanto o primeiro esteve imerso nos estudos da língua sob um enfoque materialista, histórico e dialético, o segundo herdou da perspectiva cientificista de Durkheim a noção de fato social e a visão de sujeito como sendo tanto consciente como inconsciente dos fenômenos sociais.

6. "it is known that Labov is familiar with Durkheim, that he uses the term social fact, that he accepts language to be a social fact." As traduções neste artigo são de minha responsabilidade.

7. Já Saussure, diferente de Labov, ao assumir a noção de fato social parece se referir à imposição da língua aos indivíduos (passivos) de maneira coercitiva. Ele não considera a noção de ator social, um indivíduo que teria consciência das coerções e dos fatos sociais. 


\section{Sobre a metodologia e o sujeito}

Nesta seção, a metodologia e o sujeito são abordados de forma integrada, dada a associação existente entre, por um lado, o recorte conferido ao objeto de estudo e a maneira de estudá-lo; e, por outro, uma certa visão de sujeito/indivíduo e a relação que o pesquisador estabelece com os falantes (tidos como "fontes de dados" ou como interlocutores).

Bakhtin/Voloshinov ( $\{1929] 1988)$ sugere que a ordem metodológica para o estudo da mudança na língua deve seguir a seguinte direção: relações sociais (vinculadas à infra-estrutura $=$ relações de produção) $\rightarrow$ interação verbal e comunicação (inseridas nas relações sociais) $\rightarrow$ formas e atos de fala $\rightarrow$ formas da língua. Assim, é no âmbito da mudança nas formas de interação verbal que estão inscritas em relações sociais, que as mudanças na língua devem ser estudadas. Já Labov (1972) resume o processo de mudança lingüística em três etapas: a origem da mudança, que ocorre na fala do(s) indivíduo(s) $\rightarrow$ a propagação, onde ocorre o fenômeno da variação $\rightarrow$ a regularidade no uso da nova forma. Citando o autor: "O modelo que subjaz a esta divisão tripla requer como ponto de partida uma variação em uma ou várias palavras na fala de um ou dois indivíduos"8 (1972: 01). Pode-se dizer que tanto Bakhtin como Labov baseiam o processo de mudança na interação social, sendo que o primeiro privilegia o aspecto ideológico presente nas interações - que se reflete na questão do significado social -, e o segundo privilegia as formas lingüísticas - que podem ter agregadas a si, com maior ou menor intensidade, um valor social.

Sobre uma certa concep̧cão de sujeito, as idéias de Labov e Bakhtin parecem, em certo aspecto, divergir. O sociolingüista americano, ao admitir e utilizar os dados de pesquisa de um campo de estudo (gerativismo) que lida com aspectos inatos e universais da linguagem ${ }^{9}$, aceita que os sujeitos

8. "The model which underlies this three-way division requires as a starting point a variation in one or several words in the speech of one or two individuals."

9. Citando o comentário de Labov sobre as pesquisas lingüísticas contemporâneas: "There are two major directions of linguistic research today. One is to discover the universal properties of the language faculty - the search for Universal Grammar in Chomsky's terms. This is a very important aspect of linguistic study, and I try to draw upon the results of this work as much as I can. The other direction is to examine those aspects of language that are not universal: that can and do change. [...]. I believe that studies of language change and variation have demonstrated a cumulative character, which enable us to build upon the works of our predecessors and colleagues. But they cannot 
possam ser vistos tanto como submetidos a traços lingüísticos inatos (regras gramaticais) como passíveis de serem constituídos e modificados socialmente através do processo de interação; é neste segundo campo de análise que relações entre identidade e língua (mudança) são estabelecidas. Assim, o caráter sociológico, para Labov, não seria tão determinante no funcionamento da língua (e na constituição do sujeito) como seria para Bakhtin. O inatismo e a universalidade lingüística seriam questionáveis para o filósofo russo, uma vez que o sujeito seria constituído através da língua: "é a língua que ilumina a personalidade interior e a consciência, que as cria, diferencia e aprofunda, e não o contrário [...] a evolução da consciência individual dependerá da evolução da língua, nas estruturas tanto gramaticais como concretamente ideológicas” ([1929] 1988: 188-189).

No âmbito da metodologia e do sujeito, o pesquisador laboviano assemelha-se, pelo menos no campo das pesquisas quantitativas, ao pesquisador do estruturalismo, já que, nessa perspectiva, a pesquisa gira em torno de um jogo de conceitos e abstrações que, na pretensão do pesquisador, visam explicar fenômenos da realidade - é o que ocorre, por exemplo, nos trabalhos de dimensão macro pautados nas comunidades de fala ${ }^{10}$, onde os indivíduos são tomados como tipos sociais (estratificados por sexo, escolaridade, idade...) correlacionáveis a certas variáveis lingüísticas, em um tipo abstrato de jogo de relações. Uma ressalva deve ser feita, porém, em relação às pesquisas de nível micro, que tomam como unidade de estudo os indivíduos inseridos nas redes sociais e nas comunidades de prática, nas quais o pesquisador pode assumir uma postura dialógica, ao não reduzir o falante a fornecedor de dados, reconhecendo a relação intrínseca existente entre a linguagem e as relações interpessoais (incluindo o pesquisador). Essas pesquisas de caráter micro e que focam a questão da identidade podem ser exemplificadas com os estudos de Labov em Martha's Vineyard

\footnotetext{
be pursued without reference to the more abstract, structural character of language. For those who would like to make a permanent contribution to our knowledge of language, I would suggest it is important to master both aspects of language study. Many sociolinguistic studies tend to work with isolated elements of language and do not make contact with linguistic theory. The algebra that underlies the surface of language must be incorporated into any studies of linguistic change and variation, in order to arrive at a full understanding of the causes of linguistic change." (Labov, 2005: 01)

10. A comunidade de fala é tida, para a sociolingüística quantitativa, como o lócus da análise do fenômeno lingüístico. Suas fronteiras são definidas por (i) atitudes e valores sociais compartilhados pelos falantes em relação à língua e (ii) regras gramaticais compartilhadas pelo grupo (Labov 1972).
} 
(1972), em New York (1972) e na Philadelphia (2001): no primeiro, o método de pesquisa - etnográfico - ocupou-se de significados sociais locais atribuídos às variáveis analisadas; no segundo caso, Labov focalizou a variação em grandes populações, controlando as variáveis gênero, idade, escolaridade, classe social e formalidade na fala. Esses dois estudos teriam sido pioneiros, como aponta Eckert (1996: 47), na análise lingüística pautada em uma "relação sistemática entre variação e dinâmicas sociais em ambos, nos detalhes da prática local e em padrões amplos através das comunidades"11. Nos estudos na Philadelphia, Labov se interessou por identificar os prováveis inovadores e líderes da mudança ${ }^{12}$.

Diferente do pesquisador laboviano estruturalista clássico que foca a análise lingüística na noção ampla de comunidade de fala, Bakhtin (โ195961] 2003) considera que o dialogismo é constitutivo das pesquisas que lidam com os indivíduos (como nas ciências humanas); trata-se, numa perspectiva dialógica, de ver os indivíduos como sujeitos de seu discurso e não como objeto de análise ou fonte de dados lingüísticos.

As flutuações existentes nos trabalhos de Labov em relação às dimensões macro e/ou micro de pesquisa refletem uma abordagem social da língua que, por um lado, conserva aspectos tradicionais e estruturalistas dos estudos da linguagem e, por outro, se direciona para um olhar crítico que incorpora o funcionamento social, a história dos indivíduos/sujeitos e a questão da identidade, aos estudos da linguagem.

Por fim, um outro aspecto ligado à idéia de sujeito e à metodologia está na noção de estilo. Bakhtin defende que, nos estudos do fenômeno concreto da linguagem, não é possível separar o uso gramatical das escolhas desse uso feitas pelos indivíduos. Caso, afirma o autor, o ato estilístico de escolhas fosse separado do estudo da língua, esta se restringiria a um puro fenômeno gramatical, não se tratando mais do estudo do enunciado ou do gênero discursivo. Assim, o estilo, que é parte inerente dos enun-

11. "systematic relation between variation and social dynamics in both the details of local practice and in broad patterns across communities."

12, Os fenômenos estudados por Labov compreendem, resumidamente: (i) o uso de uma alta centralização dos ditongos [ay] e [aw] como forma dos nativos da ilha de Martha's Vineyard assegurarem seus valores e identidade, em resistência aos veranistas; (ii) a relação entre altas ou baixas posições no índice socioeconômico e a freqüência de uso do -ing por adultos brancos de New York; (iii) a variabilidade na pronúncia de (dh) na Philadelphia. 
ciados, vincula diretamente a questão da identidade à língua: sujeito e linguagem estão intrinsecamente relacionados. Já Labov busca o vernáculo, que seria o estilo menos monitorado pelos falantes; com isso, a abordagem laboviana tende a se aproximar dos estudos dos fenômenos gramaticais e a se distanciar do estudo da linguagem enquanto fenômeno concreto e ideológico. Também, nesse caso, a questão da identidade seria posta de lado, visto que os falantes seriam tidos como fonte de dados de uma língua "original" de determinado grupo lingüístico. Essa questão do estilo será retomada na seção seguinte.

Sintetizando, nota-se que existe uma relação entre a visão de língua adotada pelo pesquisador, a forma de estudo do fenômeno lingüístico e uma certa concepção de sujeito: nas pesquisas labovianas quantitativas, os falantes são vistos primariamente como "fontes de dados", sendo que a relação que o pesquisador trava com os falantes tende a ser monológica (característica das ciências empíricas); já as pesquisas de natureza quantitativa de Labov se aproximam da forma dialógica bakhtiniana de fazer pesquisa, em que a língua é vista como intrinsecamente ligada à questão da identidade e ao mundo social.

\section{Variação e mudança lingüística}

Bakhtin se antecipa cerca de meio século em relação à sociolingüística americana quanto à idéia de que a mudança seria inerente à língua e refletiria variações sociais (Weedwood 2003). Mas, quais seriam as motivações para a variação/mudança segundo os teóricos em foco? Labov acredita que a língua se modifica sob a influência de variáveis de natureza externa ou interna ao sistema, sendo a primeira concernente a fatos sociais e estilísticos, e a segunda, a fatos lingüísticos. Bakhtin julga que a língua muda devido a motivações de ordem social, histórica e ideológica; não haveria, para este autor, razões puramente lingüísticas/estruturais para a língua mudar. Mesmo porque a visão de língua de Bakhtin, aliada à noção de dialogismo, não parece comportar a noção de sistema-estrutura, mas sim de devir ${ }^{13}$. Sendo a língua dialógica e, portanto, indeterminada, não há fechamento para ela, apenas efeitos de fechamento (estrutura), os quais

13. Isso não significa que não exista a forma lingüística. 
garantem a comunicação entre os sujeitos, inscritos em determinadas esferas/posições sociais e, portanto, constituídos pelas especificidades dessas esferas. Dessa forma, não seria possível conferir aos indivíduos características tipificáveis, dado que suas identidades também se transformam.

Ademais, nas pesquisas labovianas, o estudo da variação/mudança se pauta, em grande parte, na análise de micro-estruturas da língua, como aspectos fonológicos, morfológicos, sintáticos e lexicais. Para Bakhtin/Voloshinov ([1929] 1988), a mudança/evolução concerne aos aspectos semânticos, sendo que o sentido (análogo à noção de signo) diz respeito ao estudo da língua tida como enunciado, ou seja, se ocupa das relações dialógicas (e ideológicas), únicas e singulares entre as palavras, os textos, os gêneros do discurso, as linguagens, as culturas e as épocas históricas. $\mathrm{Na}$ visão de Bakhtin, o sentido não está sempre preso ao contexto histórico, social e cultural ao qual pertence: a distância (exotopia) pode favorecer o despertar de novos sentidos, já que existe a possibilidade de sentidos adormecidos depositadas em diferentes culturas passadas serem descobertos (há possibilidades semânticas infinitas na história), na grande temporalidade; isso favorece o surgimento de formas novas de percepção do mundo (Bakhtin, 2003).

A diferenciação entre Labov e Bakhtin acerca das motivações para a mudança permite reconhecer nesses autores diferentes perspectivas sociais sobre a língua: Labov não é categórico quanto à determinação social da mudança na língua, apesar de sê-lo na visão de que a mudança é própria da língua. Para Labov não é sempre que a língua varia devido a forças sociais, cabendo também à própria estrutura da língua a possibilidade de modificações. Esse último fato seria alvo de crítica por uma abordagem sociológica mais radical: como seria possível a língua modificar sem uma motivação de ordem social, uma vez que a língua é necessariamente social?

Bakhtin/Voloshinov, por outro lado, vê as motivações para a mudança como sendo de cunho totalmente social, material e histórico, daí sua abordagem poder ser identificada como sociológica/marxista. E a variação/ mudança permeia a seguinte engrenagem: diferentes esferas sociais constituem diferentes formas de comunicação verbal, que se alteram e se produzem mútua e historicamente. Para Bakhtin/Voloshinov, a língua muda porque diferentes significados sociais são atribuídos aos elementos lingüísticos, fruto das relações (conflituosas) existentes entre diferentes grupos sociais. Nesse caso, o estudo da mudança deve levar em conta um olhar 
amplo sobre o funcionamento da sociedade atual, considerando a tensão existente entre os diversos grupos sociais (o que inclui as questões de gênero, etnia, raça, religião, condição econômica, escolaridade, idade, profissão, crenças e valores, etc).

No que tange à variação, a dominação de uma variante em relação a outra, na perspectiva de Bakhtin/Voloshinov ([1929] 1988), depende da língua, da época, dos grupos sociais e do objetivo dos contextos; deve-se, nesse caso, levar em conta o horizonte apreciativo dos grupos e até mesmo as lutas/confrontos existentes entre eles. Já na visão de Labov, a questão ideológica não é considerada prioritária no processo de variação; trata-se de levar em conta os fatores sociais e lingüísticos, sendo que a ideologia é vista em relação aos primeiros fatores através de, por exemplo, testes de atitudes. Nesse caso, a percepção da influência de aspectos ideológicos na mudança da língua seria mais evidente quando os falantes tivessem consciência da língua (das variantes) que falam, pois estigmatizariam ou avaliariam como prestigiadas determinadas formas em detrimento de outras.

Sobre o indivíduo no processo de mudança lingüística, Labov localiza a importância do papel da identidade/identificação a um certo grupo. Exemplificando: o lingüista americano, em suas pesquisas sobre variação na ilha de Martha's Vineyard (1972), salientou que o intuito dos nativos de marcarem suas identidades, frente à invasão turística, intensificou certos usos lingüísticos; já nos estudos de variação na Philadelphia (2001), Labov buscou identificar os líderes da mudança lingüística em certa comunidade. Para Bakhtin/Voloshinov, diferentemente, a mudança seria possível se as relações de produção mudassem, o que permitiria uma mudança no âmbito ideológico e, portanto, lingüístico (semântico). A mudança dependeria, nesse caso, de um grupo de indivíduos em interação que motivasse mudanças na realidade social e, conseqüentemente, na linguagem.

Sobre as variações lingüísticas nos indivíduos, segundo Labov (2003), essas seriam condicionadas pelos seguintes fatores: (i) as relações entre os interlocutores, particularmente as relações de poder e solidariedade entre eles; (ii) o contexto social mais amplo - escola, trabalho, vizinhança; e (iii) o tópico. Chama a atenção a semelhança entre esses critérios e os utilizados para a delimitação dos gêneros discursivos segundo a ótica bakhtiniana. Colocando ambos em perspectiva, tem-se que o fator (i) de Labov associase à noção de destinatário e de interlocutor que o falante possui; o fator (ii) 
refere-se à esfera social de uso da linguagem; e o (iii) associa-se à finalidade discursiva dos falantes.

$\mathrm{Na}$ abordagem laboviana, a variação estilística se vincula ao monitoramento da fala, que implica um certo apagamento do vernáculo - estilo casual, procurado pelo sociolingüista. Nesse caso, a variação estilística poderia mostrar apenas uma variação momentânea da língua, em decorrência de o falante monitorar a sua fala conforme a posição social que ocupa, o seu destinatário ou o tema que aborda. Com isso, a variação estilística acaba provocando no pesquisador uma certa suspeita, conferindo àquela um potencial menor para explicar os fenômenos da mudança.

$\mathrm{Na}$ abordagem bakhtiniana, o indivíduo trava relações de valor com seu objeto do discurso/de sentido. Tal relação confere a esse objeto características individuais do falante - a expressividade do locutor -, que podem ser exemplificadas pela entonação expressiva que os falantes atribuem a seus enunciados. A expressividade se associa à significação lingüística (ao invés da forma lingüística), o que implica que, sendo a mudança na língua uma mudança semântica, ela necessariamente envolve uma mudança de valores dos indivíduos em relação ao seu objeto de discurso. É quando a palavra muda de um contexto apreciativo para outro que sua função/significação também muda. Ressalta-se, porém, que os indivíduos não criam uma forma lingüística nova, sendo o falante limitado pelas formas já existentes e pelas situações de comunicação verbal existentes em seu grupo. A inovação lingüística só seria possível se essas situações se alterassem, por influência de motivações socioeconômicas mais amplas.

Diferentemente de Labov, Bakhtin atribui à relação (de valor) que o falante estabelece com aquilo que fala um lugar importante no processo de mudança lingüística, sendo a língua vista como discurso e não como um sistema abstrato de signos. Nas palavras de Bakhtin/Voloshinov ([1929] 1988: 135-136), "A evolução semântica na língua é sempre ligada à evolução do horizonte apreciativo de um dado grupo social e a evolução do horizonte apreciativo [...] é inteiramente determinada pela expansão da infra-estrutura econômica". Apesar de a variação estilística (individual) não ocupar um lugar central na teoria laboviana, acredito que a valoração social de um certo grupo em relação às variáveis lingüísticas motiva, muito mais do que comumente se pensa, a mudança na língua. 
Ademais, é importante destacar o lugar conferido às estratificações na garantia da diversidade (e mudança) lingüística. Para Labov, há uma correlação entre as estratificações sociais (gênero, escolaridade, idade...) e o uso da língua. Na perspectiva de Bakhtin, as estratificações lingüísticas estão intrinsecamente vinculadas aos diferentes horizontes apreciativos (percepções valorativas), constituídos sócio-historicamente, que os indivíduos possuem em relação ao seu objeto discursivo. Esse ponto de vista bakhtiniano reforça a importância das variáveis estilísticas (as relações valorativas dos indivíduos) como motivadoras da mudança: todo uso lingüístico está, necessariamente, associado a índices sociais de valor.

Resumindo, as motivações para a mudança da língua incluem, para Labov, aspectos sociais e estruturais, enquanto para Bakhtin, não haveria motivações puramente lingüísticas para a língua mudar: a diferença entre os dois autores reside na visão de língua que possuem - como sistema (Labov) ou como devir (Bakhtin). Aliado a esse aspecto está o fato de que os fenômenos estudados dentro de um enfoque laboviano tendem a se ater a micro-estruturas da língua, ao passo que uma abordagem bakhtiniana tende a valorizar os aspectos semânticos (ideológicos). Além disso, Labov reconhece o papel da identidade no processo de funcionamento da língua, mas Bakhtin parece ser mais radical quanto a esse aspecto ao defender que os sujeitos travam relações de valor com o seu objeto de discurso, sendo que tal relação, necessariamente, produz efeitos sobre o funcionamento da língua.

\section{Língua, sociedade e identidade}

Sobre a relação entre língua, sociedade e identidade, a definição de Labov de língua como fato social, entendida nos termos durkheiminianos, postula: (i) uma realidade social que existe anterior à língua, a qual é 'imposta' aos indivíduos pela coerção; (ii) os indivíduos, ao mesmo tempo em que são submetidos ao sistema da língua, têm consciência dele e podem fazer escolhas quanto ao estilo lingüístico a adotar. Bakhtin se distancia da perspectiva de Labov ao atribuir à língua, por exemplo, a característica do dialogismo: (i) a língua, ao mesmo tempo em que é constituída pelo mundo, constitui a realidade; (ii) os indivíduos se constituem na relação uns com os outros, ou seja, na interação sócio-histórica-verbal. Os indivíduos não são externos à linguagem, mas esta é constitutiva deles (de sua cons- 
ciência). Dado o caráter dialógico das interações sociais e lingüísticas, Bakhtin considera o papel do outro - como ativo no processo de comunicação a base para se compreender a comunicação discursiva real. Tal papel tende a ser suavizado nas pesquisas de cunho laboviano como, por exemplo, no caso das entrevistas, em que o interlocutor do falante (que é o pesquisador) tende à passividade e à "não perturbação" da fala do outro - apesar de mesmo o silêncio do pesquisador produzir uma atitude responsiva no entrevistado.

Ademais, os objetos de estudo de ambas as abordagens são diferentes: para Labov interessam os aspectos fonológicos, morfológicos, sintáticos e lexicais da língua, admitindo ser possível que a língua mude em decorrência do próprio funcionamento do sistema lingüístico, o que, na compreensão de Bakhtin de língua como um fenômeno concreto, seria inaceitável ${ }^{14}$, já que o teórico russo se ocupa do estudo da natureza dos enunciados e dos gêneros discursivos, e sugere que esse estudo é condição para se compreender as unidades da língua (tida como sistema). Tal diferença de objetos mostra que no pensamento de Bakhtin há uma relação intrínseca entre língua, sujeito e sociedade, relação que para Labov é relativa.

O lingüista americano considera língua, sociedade e indivíduo como três categorias diferentes que se relacionam entre si; tal relação se evidencia nas correlações que o pesquisador estabelece entre variáveis lingüísticas e os indivíduos categorizados mediante traços sociais, como gênero, escolaridade, posição socioeconômica, etc. Para Bakhtin/Voloshinov, existem relações de produção que são anteriores aos indivíduos; os indivíduos se constituem através dessas relações que são atravessadas pela linguagem; essa, por sua vez, é ideologicamente marcada e, por isso, constrói uma certa visão de mundo (não um mundo). As mudanças, nesta perspectiva, dependem de revoluções que ocorrem no nível das relações de produção, conferindo novos significados sociais à realidade.

Contudo, apesar de o indivíduo, na teoria laboviana, ser tradicionalmente visto como ponto de articulação entre dados lingüísticos e categorias sociais, Labov reconhece que, para explicar certos fenômenos da mu-

14. Apesar de Bakhtin (2003) estar interessado no aspecto discursivo da língua, ele não descarta o estudo da língua tida como sistema abstrato; só relega esse estudo ao cientificismo do campo lingüístico. Contudo, defende que é através do entendimento do funcionamento dos enunciados e dos gêneros discursivos que é possível superar as simplificações da Lingüística. 
dança, torna-se necessário não apenas identificar o sujeito, mas conhecê-lo - conhecer sua história, suas redes de relações, etc. Para tanto, pode-se tomar como unidade de análise as redes sociais ou as comunidades de prática, ambas envolvendo o indivíduo na trama das relações sociais, seja pelo rastreamento dos grupos de interação aos quais um indivíduo em sua comunidade decide pertencer (redes sociais), ou pela identificação de práticas compartilhadas por indivíduos nas quais certos elementos lingüísticos são re-significados socialmente (comunidades de prática). Nesses dois casos, a dimensão de estudo passaria do nível macro (pautado na definição do indivíduo com base em tipologias sociais) para um nível micro. No nível micro, as pesquisas que levam em conta as comunidades de prática valorizam as variações estilísticas individuais para o estudo da mudança, uma vez que elas se vinculam à construção das identidades dos indivíduos.

A relação entre língua e identidade na abordagem de Bakhtin é visível na idéia de que o sujeito se constitui na sua inserção nos diferentes modos de comunicação verbal historicamente produzidos. É através da interação entre os indivíduos que os modos de comunicação verbal, já cristalizados ou não, existem. Tais modos vinculam-se, segundo Bakhtin, aos modos de relações de cada época histórica, sendo essas relações economicamente constituídas.

Em poucas palavras, pode-se afirmar que a diferença crucial entre Labov e Bakhtin reside na articulação que os dois estabelecem entre língua, identidade e realidade social. Na visão de Labov, essa articulação, por um lado (em pesquisas de caráter macro), tende a um jogo abstrato de relações quantitativas e, por outro, tende a reconhecer a relação intrínseca entre o processo de constituição das identidades e o funcionamento da língua. $\mathrm{Na}$ ótica de Bakhtin, língua, sociedade e sujeitos estão interligados: a mudança na língua ocorre em virtude de uma mudança nas formas de interação verbal (vinculadas a diferentes esferas sociais) entre os sujeitos, sendo que a relação entre língua e mundo não é unidirecional, mas de mão dupla.

\section{Conclusão}

Objetivou-se, neste artigo, estabelecer certas aproximações e distanciamentos entre os pensamentos de Bakhtin e de Labov. A possibilidade de diálogo entre os dois se sustenta no fato de compartilharem um interesse pelos estudos do funcionamento da língua a partir de uma ótica social, 
sendo a língua vista como heterogênea, plural e em processo de mudança. É certo que as posturas empírica e filosófica de Labov e de Bakhtin, respectivamente, marcam distinções evidentes entre os autores, como, por exemplo, a possibilidade de sistematização da variação/mudança lingüística defendida por Labov em contraposição à inviabilidade dessa sistematização segundo uma concepção de língua tida como enunciado/discurso e não como sistema/estrutura.

Em termos de tradições sociológicas presentes nas teorias de Labov e de Bakhtin, nota-se que o primeiro compartilha com a escola de Durkheim a visão de língua como fato social, sendo que ela existe exterior aos sujeitos; o segundo se apropria do materialismo histórico-dialético para definir a língua/signo em relação ao contexto socioeconômico das relações de produção.

As aproximações feitas em relação ao procedimento metodológico, à concepção de sujeito, às motivações da mudança, às variações estilísticas e às relações entre linguagem, indivíduo e realidade social pretenderam mostrar que um diálogo entre Bakhtin e Labov é possível em termos teóricos e metodológicos, desde que seja estabelecida uma relação intrínseca entre o funcionamento da língua, a questão da identidade e a visão de mundo social como sendo dinâmico, plural, conflituoso e dialógico.

Por fim, acredito que ao se estabelecer um diálogo entre a abordagem discursiva de Bakhtin/Voloshinov e a sociolingüística de Labov, coloca-se em tela, por exemplo, a possibilidade de um enfoque discursivo (envolvendo os processos de construção dos sentidos) tanto para o estudo das formas lingüísticas (aspectos sintáticos, lexicais, morfológicos e fonético-fonológi$\cos )$, como para a análise do processo de variação/mudança da língua. Resumindo, a abordagem discursiva, apresentada neste artigo, aplicada, por exemplo, ao estudo da variação lingüística implica que: (i) as variáveis lingüísticas são significadas/valoradas socialmente e, por isso, vinculam-se ao processo de constituição das identidades dos sujeitos, o que se evidencia nas relações de valor que os sujeitos estabelecem com as variantes; (ii) em virtude de (i), a variação lingüística pode ser vista como lugar de manifestação do discurso.

Recebido em novembro de 2007 Aprovado em dezembro de 2008 E-mail: crisgorski2@hotmail.com 


\section{REFERÊNCIAS BibLIOGRÁFICAS}

BakHTin, Mikhail \& Voloshinov, Valentin Nikolaevich. 1988. Marxismo e Filosofia da Linguagem [1929] (trad. Michel Lahud; Yara F. Vieira). São Paulo: Editora Hucitec.

BAkHtın, Mikhail. 2003. Estética da Criação Verbal (trad. Paulo Bezerra). $4^{\mathrm{a}}$ ed. São Paulo: Martins Fontes.

. Os gêneros do discurso [1952-53]. In: Mikhail Bakhtin, 2003. . O problema do texto [1959-61]. In: Mikhail BaKhtin, 2003.

. Metodologia das ciências humanas [1974]. In: Mikhail BAKHTIN, 2003.

Brandist, Craig. 2006. Mikhail Bakhtin e os primórdios da sociolingüística soviética (trad. Carlos Alberto Faraco). In: Carlos Alberto Faraco; Cristóvão Tezza \& Gilberto de CASTRO (orgs). Vinte ensaios sobre Mikhail Bakhtin. Petrópolis: Vozes: 67-88.

. 2005. Marxism and the Philosophy of Language in Rússia in the 1920s and 1930s. Historical Materialism, Leiden, 13: 63-84. Disponível em <www.brill.nl> Acesso em: 05/2006.

Durkheim, Émile. 1973. As regras do método sociológico. In: Os Pensadores.

São Paulo: Abril S.A. Cultural e Industrial: 373-464.

ECKert, Penelope. 1996. (ay) Goes to the City: Exploring the expressive use of variation. In.: G. GuY; C. Feagin; D. Schiffrin, \& J. Baugh, (eds.). Towards a social science of language. Vol 1: Variation and change in language and society. Amsterdam/Philadelphia: J. Benjamins: 47-68.

FigueroA, Ester. 1994. Sociolinguistic metatheory. Pergamon.

Giddens, Anthony. 1998. Política, Sociologia e Teoria Social (trad. Cibele S.

Rizek). São Paulo: Editora da Unesp.

Labov, William. 1972. Sociolinguistic Patterns. Pennsylvania: University of Pennsylvania Press.

. 1994. Principles of Linguistic Change: Internal Factors. Massachusetts/

Oxford: Blackwell.

. 2001. Principles of Linguistic Change: Social Factors. Massachusetts/

Oxford: Blackwell.

. 2003. Some sociolinguistic principles. In: C. B. Paulston \& G. R. TuCKer (eds.). Sociolinguistics: the essencial readings. Oxford: Blackwell. .2005. Entrevista com William Labov: Sociolinguistics by its creator.

Revista Letra Magna, ano 2, 2. Disponível em <www.letramagna. com.br> Acesso em: 10/2005. 
LÄhteenmäKï, Mika. 2006. Da crítica de Saussure por Voloshinov e Iakubinskii. In: Carlos Alberto FARACO; Cristóvão TeZZA \& Gilberto de CAstro (orgs). Vinte ensaios sobre Mikhail Bakbtin. Petrópolis: Vozes: 190-207.

. 2005. Estratificação social da linguagem no "discurso sobre o romance": o contexto soviético oculto. In: Ana ZandwaIs (org). Mikhail Bakhtin: Contribuições para a Filosofia da linguagem e Estudos Discursivos. Porto Alegre: Editora Sagra Luzzatto: 41-58.

Severo, Cristine Gorski. 2007. Por uma perspectiva social dialógica da linguagem: repensando a noção de indivíduo. Tese (Doutorado) - Universidade Federal de Santa Catarina, Programa de Pós-Graduação em Lingüística. Florianópolis: $255 \mathrm{f}$.

WeEdwood, Barbara. 2003. História concisa da Lingüistica (trad. Marcos Bagno). São Paulo: Parábola. 